\title{
EDUCAÇÃO INCLUSIVA NA FORMAÇÃO DE PROFESSORES DE ARTES VISUAIS NA UNIVERSIDADE DO ESTADO DA BAHIA E NO ESTADO DE MINAS GERAIS
}

\author{
INCLUSIVE EDUCATION IN THE TRAINING OF VISUAL ARTS TEACHERS AT THE STATE \\ UNIVERSITY OF BAHIA AND IN THE STATE OF MINAS GERAIS
}

\section{EDUCACIÓN INCLUSIVA EN LA FORMACIÓN DE PROFESORES DE ARTES VISUALES EN LA UNIVERSIDAD DEL ESTADO DE BAHIA Y EN EL ESTADO DE MINAS GERAIS}

\author{
Natália Adriana Couy Pinto ${ }^{1}$ \\ Menderson Correia Bulcão2 \\ Ricael Spirandeli Rocha ${ }^{3}$
}

\begin{abstract}
RESUMO
Pensando no ensino para todos e na construção de uma sociedade inclusiva para com as diferenças e singularidades, este estudo teve como objetivo investigar a partir de documentos pedagógicos, os componentes curriculares relacionados à educação inclusiva nos cursos presenciais de Licenciatura em Artes Visuais na Universidade do Estado de Minas Gerais (UEMG) - Campus Escola de Design e 0 mesmo curso na Universidade do Estado da Bahia (UNEB) associados a todos os campi da Universidade. Metodologicamente preocupou-se em analisar e comparar os currículos dos cursos de licenciatura das instituições, visto que as realidades das Universidades com base nesses documentos foram debatidas e comparadas entre si, bem como frente ao que diz a legislação, caracterizando a pesquisa como documental e comparativa. Como resultados, não podemos afirmar que as temáticas do contexto inclusivo não se fazem presentes por meio dos diálogos e das vivências do dia a dia nas Universidades referidas, mas sim, apontar essa fragilidade que corresponde em ambos os currículos, que não especifica e nem determina pautas específicas para se contemplar a temática, deixando a mesma para o acaso das aulas, dos momentos e das disciplinas.
\end{abstract}

PALAVRAS-CHAVE: Educação Inclusiva. Formação Docente. Artes Visuais.

\section{ABSTRACT}

Thinking about teaching for all and building an inclusive society towards differences and singularities, this study aimed to investigate, from pedagogical documents, the curricular components related to inclusive education in the on-site courses of Licentiate in Visual Arts at the University of State of Minas Gerais (UEMG) - School of Design Campus and the same course at the State University of Bahia (UNEB) associated with all the University's campuses. Methodologically, it was concerned with analyzing and

\footnotetext{
${ }^{1}$ Mestranda em Educação pela Universidade Federal de Ouro Preto. Especialista em Atendimento Educacional Especializado e pós graduanda em Docência com Ênfase em Educação Inclusiva; em Direitos Humanos e em Metodologia do Ensino da Arte. Possui graduação em Artes Visuais pela Universidade do Estado de Minas Gerais e atua como Professora de Arte para alunos da Educação Básica. E-mail: nataliacouy@yahoo.com.br

2 Bacharel (UFRB - 2015) e Mestre (UFBA - 2020) em Museologia. Museólogo ( $n^{0}$. de registro 0413.I - COREM 1R/COFEM). Artista Visual. Cenógrafo. Produtor Cultural. Curador. Conselheiro (2018-2020) do Conselho Regional de Museologia - Corem $1 \mathrm{R}$. Mestre em Museologia pelo Programa de Pós-graduação em Museologia (PPGMuseu) - Faculdade de Filosofia e Ciências Humanas (FFCH) - Universidade Federal da Bahia (UFBA). .Bacharel em Museologia pela Universidade Federal do Recôncavo da Bahia (2015). E-mail: menderson1@gmail.com

3 Docente do Instituto Federal de Educação, Ciência e Tecnologia de Minas Gerais (IFMG) - Campus Avançado Arcos; Especialista em Educação Profissional e Tecnológica Inclusiva; Mestrando em Educação Tecnológica pelo Programa de Pós-Graduação em Educação Tecnológica do Instituto Federal de Educação, Ciência e Tecnologia do Triângulo Mineiro (PPGET-IFTM); Professor de Educação Básica de cursos técnicos pela Secretaria Estadual de Minas Gerais (SEE/MG). Integrante do grupo de pesquisa "GPETEC - Grupo de Pesquisa em Educação, Tecnologia e Ciências" na linha de pesquisa "Desenvolvimento de aplicativos tecnológicos e softwares educacionais" do IFTM Campus Uberlândia-Centro; Editor Adjunto da revista MultiAtual. E-mail: ricael.edu@gmail.com
}

Revista de Ciências Humanas, Frederico Westphalen - RS, v. 22, n.2, p. 176-193, maio/ago. 2021.

Recebido em: 20/05/2021 $\quad$ Aceito em: 21/06/2021


comparing the curricula of the institutions' degree courses, since the realities of the Universities based on these documents were debated and compared with each other, as well as against what the legislation says, characterizing the research as documentary and comparative. As a result, we cannot say that the themes of the inclusive context are not present through the dialogues and daily experiences in the mentioned Universities, but rather, point out this weakness that corresponds in both curricula, which does not specify or determine specific agendas to contemplate the theme, leaving it to the chance of classes, moments and disciplines.

KEYWORDS: Inclusive Education. Teacher Training. Visual Arts.

\section{RESUMEN}

Pensando en la enseñanza para todos y la construcción de una sociedad inclusiva hacia las diferencias y singularidades, este estudio tuvo como objetivo investigar, a partir de documentos pedagógicos, los componentes curriculares relacionados con la educación inclusiva en los cursos presenciales de Licenciatura en Artes Visuales de la Universidad Estatal de Minas Gerais (UEMG) - Campus de la Escuela de Diseño y el mismo curso en la Universidad Estatal de Bahía (UNEB) asociado a todos los campus de la Universidad. Metodológicamente, se preocupó por analizar y comparar los planes de estudio de los cursos de pregrado en las instituciones, ya que las realidades de las Universidades a partir de estos documentos fueron debatidas y comparadas entre sí, así como con lo que dice la legislación, caracterizando la investigación como documental. y comparativo. En consecuencia, no podemos decir que los temas del contexto inclusivo no estén presentes a través de los diálogos y vivencias cotidianas en las Universidades mencionadas, sino señalar esta debilidad que corresponde en ambos currículos, que no especifica ni determina agendas específicas para contemplar el tema, dejándolo al azar de clases, momentos y disciplinas.

PALABRAS CLAVE: Educación inclusiva. Formación de profesores. Artes visuales.

\section{INTRODUÇÃO}

Os Para discutir a inclusão de Pessoas com Deficiência (PCD) em quaisquer condições e cenários, compreende-se a necessidade de considerar a temática da diversidade, uma vez que a mesma está presente em todos os aspectos humanos. Esses aspectos resultam nas diferenças, que são marcadas por uma pluralidade de características, sejam culturais, religiosas, sociais, ou mesmo de diferenças individuais como gênero, faixa etária, etnia, especificidade corporal, de aprendizagem, dentre outras características pessoais e sociais.

Já as desigualdades representam os preconceitos, as oportunidades e tratamentos diferentes para grupos heterogêneos e 0 acesso desigual a direitos políticos, à educação e à cultura (BARROS, 2018). No entanto, na contemporaneidade, a pauta da inclusão é amparada por legislações, pesquisas acadêmicas, políticas públicas, pela atuação do movimento social em prol dos direitos das pessoas com deficiência e, especialmente pelos sujeitos que demandam estes direitos sociais, fundamentais e humanos.

Nesse sentido, esta temática se trata de uma pauta social que envolve e requer a participação de todos, uma vez que a Constituição Federal (BRASIL, 1988) não diferencia os sujeitos em seus direitos e deveres. A sociedade, a União e os espaços públicos devem ser 
suporte para que a inclusão aconteça efetivamente desde cedo na vida das pessoas com deficiência, sem segregação deste ou de quaisquer outros grupos.

A partir dessa compreensão, evidencia-se que a Constituição Federal (CF) de 1988, em seu artigo $5^{\circ}$, garante a todos os mesmos direitos, sendo que "todos são iguais perante a lei, sem distinção de qualquer natureza, garantindo-se aos brasileiros e aos estrangeiros residentes no País a inviolabilidade do direito à vida, à liberdade, à igualdade, à segurança e à propriedade" (BRASIL, 1988).

O direito de todos ao ensino e a garantia de educação em todo o país também está assegurado no texto da CF. No que se refere à inclusão escolar, a Declaração de Salamanca, importante documento no histórico da educação inclusiva, teve grande influência sobre a formulação de políticas públicas para a inclusão, que se originou da Conferência Mundial sobre Educação Especial de 1994 (SALAMANCA, 1994).

Tal documento defende que os sistemas educacionais considerem a diversidade de características e necessidades de todos os estudantes, sendo por meio de escolas regulares a forma mais eficaz de combater atitudes discriminatórias com orientação inclusiva (BRASIL, 1994).

Em 1996 foi promulgada a Lei de Diretrizes e Bases da Educação Nacional (LDB) $n^{0}$ 9.394/96 (BRASIL, 1996), a lei possui um capítulo específico que trata da educação inclusiva, o que antes era percebido de maneira explícita na CF. A lei discorre, dentre outros temas, da finalidade de pleno desenvolvimento do educando e do princípio da igualdade de condições e permanência na escola.

Apresentando especificamente os direitos educacionais do estudante com deficiência, a Lei Brasileira de Inclusão (LBI), n 13.146 de 06 de julho de 2015, marca uma série de regulamentações para a educação inclusiva, e apresenta determinações que permeiam todos os níveis de ensino da escola regular, seja na esfera pública ou privada. Ainda, apresenta vários recursos na área da educação, medidas que contribuem para o exercício do direito dos estudantes com deficiência, propondo "assegurar e a promover, em condições de igualdade, 0 exercício dos direitos e das liberdades fundamentais por pessoa com deficiência, visando à sua inclusão social e cidadania" (BRASIL, 2015).

Isto posto, pensando no ensino para todos e na construção de uma sociedade inclusiva para com as diferenças e singularidades, indaga-se: Como identificar e apontar quais são as realidades curriculares e as tensões entre a formação docente e a educação inclusiva, no que diz respeito aos direitos educacionais das pessoas com deficiência? Há, de fato, componentes 
curriculares em cursos de graduação com fomento à educação e com foco nos alunos com necessidades educacionais específicas?

Nesse sentido, esta pesquisa objetiva-se em investigar, a partir de documentos pedagógicos, os componentes curriculares relacionados à educação inclusiva nos cursos presenciais de Licenciatura em Artes Visuais na Universidade do Estado de Minas Gerais (UEMG) - Campus Escola de Design; e o mesmo curso na Universidade do Estado da Bahia (UNEB) associados a todos os campis da Universidade.

A pesquisa está estruturada da seguinte forma: a fundamentação teórica, trazendo a compreensão sobre o panorama histórico da evolução dos direitos das pessoas com deficiência e destaca a exposição dos termos da legislação em relação aos direitos dos estudantes com deficiência; em seguida é abordado uma pauta sobre a formação de professores para educação inclusiva, destacando os cursos de Artes Visuais na UNEB e UFMG. Logo após, apresenta-se à metodologia da pesquisa, dados sobre o cenário e como foi realizado, seguido pelos resultados e fomentando discussões. Por fim, ocorrem as considerações finais da pesquisa.

\section{BREVE PANORAMA DOS DIREITOS À EDUCAÇÃO INCLUSIVA NO BRASIL}

A inclusão existe não apenas para que pessoas com deficiência sejam inseridas nos mais diversos campos da sociedade, mas sim, para que quaisquer pessoas e grupos sociais que estão à margem da sociedade e dos grupos ditos normais (sendo estes aqueles que fogem de qualquer padrão excludente historicamente imposto e perpetuado na e pela sociedade) sejam pertencentes de fato das pautas da sociedade e incluídos em todos os campos, buscando a extinção desses padrões humanos excludentes criados ao longo da história.

O que faz uma escola ser inclusiva é a promoção de acesso, tanto intelectual quanto físico, em iguais condições para todos os alunos (MANTOAN, 2005). Isso não significa acesso normativo igualitário, mas sim acesso diferenciado conforme as necessidades educacionais dos estudantes, tendo como ponto de partida:

Um bom projeto pedagógico, que começa pela reflexão. Diferentemente do que muitos possam pensar, inclusão é mais do que ter rampas e banheiros adaptados [...]. Os alunos precisam de liberdade para aprender do seu modo, de acordo com as suas condições. $E$ isso vale para os estudantes com deficiência ou não (MANTOAN, 2005, s. p).

Incluir não consiste apenas em promover um espaço territorial acessível, mas sim proporcionar acesso das mais variadas formas, sejam elas atitudinais, conceituais, educacionais 
e quaisquer outras, em comuns condições para todos, visto que as pessoas possuem habilidades e características diferentes.

Conforme pontua Lucia Reily, "a diversidade se acentuou no novo milênio nas escolas brasileiras a partir do movimento de inclusão, que assegura espaço no ensino regular para alunos com deficiências que antes estariam excluídos da escola ou teriam frequentado escolas especiais ou apenas atendimento clínico" (REILY, 2010, p. 86). Isto significa que a escola possui o papel de fomentar a educação objetivando alcançar o pleno desenvolvimento da pessoa e que a mesma garante a igualdade de condições para o acesso e permanência na escola (BRASIL, 1988).

No que se refere a legislação, a LBI garante a "inclusão em conteúdos curriculares, em cursos de nível superior e de educação profissional técnica e tecnológica, de temas relacionados à pessoa com deficiência nos respectivos campos de conhecimento" (BRASIL, 2015, s. p), o que vai de encontro com a obrigatoriedade da construção de currículos em cursos de licenciatura que abrangem a temática da inclusão.

Além disso, na mesma lei, Brasil $(2015$, s. p) destaca que "caberá ao poder público promover a inclusão de conteúdos temáticos referentes ao desenho universal ${ }^{4}$ nas diretrizes curriculares da educação profissional e tecnológica e do ensino superior e na formação das carreiras de Estado". Ainda explicita, em seu Art. 27, questões que tangenciam a obrigatoriedade do acesso, permanência e pós-permanência da pessoa com deficiência no ambiente educacional:

A educação constitui direito da pessoa com deficiência, assegurado sistema educacional inclusivo em todos os níveis e aprendizado ao longo de toda a vida, de forma a alcançar o máximo desenvolvimento possível de seus talentos e habilidades físicas, sensoriais, intelectuais e sociais, segundo suas características, interesses e necessidades de aprendizagem (BRASIL, 2015).

Além de tais dispostos na LBI, percebe-se que já havia alguns informas sobre inclusão e a garantia desses direitos a Pessoa com Deficiência na Lei de Diretrizes e Bases da Educação Nacional (LDB, 1996) garantindo a igualdade de condições para o acesso e permanência na escola No artigo $4^{\circ}$, inciso III, afirma-se que:

O dever do Estado com a educação escolar pública será efetivado mediante a garantia de [...] atendimento educacional especializado gratuito aos educandos com deficiência, transtornos globais do desenvolvimento e altas habilidades ou

\footnotetext{
4 Segundo a LBI (2015), o desenho universal é "Il - desenho universal: concepção de produtos, ambientes, programas e serviços a serem usados por todas as pessoas, sem necessidade de adaptação ou de projeto específico, incluindo os recursos de tecnologia assistiva".
} 
superdotação, transversal a todos os níveis, etapas e modalidades, preferencialmente na rede regular de ensino (BRASIL, 1996, s. p).

Mesmo se tratando de legislações relativamente recentes, a inclusão de estudantes com deficiência nas escolas antecede a LDB e a década de 90. Porém, é importante ressaltar que do século XVI até meados do século $X X$ a sociedade vivia o período de Integração, o qual era marcado na "Educação voltada às questões clínicas, na reabilitação individual, gerando uma modalidade de "educação especial" dentro da instituição regular de ensino" (CONTAGEM, 2016, p. 6).

Este período mostra que 0 acolhimento era realizado ao aluno, mas os modelos pedagógicos buscavam um aluno "ideal" em turmas homogêneas, excluindo aqueles que não "cabiam" nos modelos e padrões existentes pré-estabelecidos, o que valia não apenas para estudantes com deficiência, mas para quaisquer outros que não estivessem "de acordo" com os padrões estabelecidos: os mais pobres, os alunos fora da idade padrão, alunos com transtornos etc.

\section{EDUCAÇÃO INCLUSIVA NA FORMAÇÃO DE PROFESSORES}

No contexto da formação de professores, a Lei n. 10.436 , de 24 de abril de 2002 (BRASIL, 2002), que dispõe sobre a Língua Brasileira de Sinais - LIBRAS, e regulamenta a sua inclusão como componente curricular nos cursos de formação de professores para os níveis fundamental, médio e superior e para os cursos de pedagogia, bem como a LBI (2015), para a criação de novos cursos nos níveis de aperfeiçoamento, graduação e pós-graduação no campo da Educação Inclusiva.

A Educação Inclusiva tem como um de seus papéis, fomentar a acessibilidade para as pessoas com deficiência, uma vez que a LBI é "destinada a assegurar e a promover, em condições de igualdade, o exercício dos direitos e das liberdades fundamentais por pessoa com deficiência, visando à sua inclusão social e cidadania" (BRASIL, 2015).

A contextualização de práticas na educação inclusiva tem contribuído para a dinamização das noções e conceitos do tema enquanto um vetor para o desenvolvimento social e cultural. No entanto, m um contexto educacional dinâmico e cheio de marcadores identitários é fundante a estruturação de programas que contemplem a diversidade em sua inteireza.

A construção das políticas públicas educacionais exterioriza uma demanda social de direitos civis, fundamentais e humanos. Deste modo, pensar em contextos inclusivos 
educacionais é um paradigma a ser implementado como uma forma de se alcançar a cidadania e a plenitude dos direitos. Conforme Candeias (2009), este contexto inclusivo se refere a potencialidades inclusivas com dimensões simbólicas, culturais e educacionais.

Neste sentido, a perspectiva da educação inclusiva no espaço escolar é fundamental para estruturar as questões do ensino na educação básica. Essas potencialidades não se materializam apenas por meio da educação formal, mas também por meio de toda a prática social que os contextos inclusivos envolvem "uma dimensão escolar e uma extra-escolar que é fundamental acautelar e desenvolver", pois é na escola, assim como em outros diversos espaços, "que essas crianças, jovens ou adultos se encontram, cruzam e interagem com os outros iguais a si e os outros diferentes", e todos os contextos inclusivos, o que envolve todos os espaços, devem ser pautados para que a escola não fique "amputada" junto à discussão (CANDEIAS, 2009, p. 110-111).

Em um sistema social como o Brasil, em que as desigualdades sociais, econômicas e políticas administrativas são evidenciadas nas relações socioeconômicas e atravessadas nos espaços educativos, a formação de professores perpassa pelas linguagens e pelas imersões em espaços desiguais para compreender as diferenças e mitigar as desigualdades nos processos de acesso à educação, cultura, infraestrutura e outros.

A Política Nacional de Educação Especial na Perspectiva da Educação Inclusiva (BRASIL, 2008) foi construída pela participação de setoriais da sociedade civil e dos organismos dos entes federados. Deste modo, este pressuposto se alinha à política pública no âmbito internacional que propõe a educação inclusiva como eixo fundante para uma sociedade emancipada.

De acordo com os pressupostos normativos, os princípios se delineiam pelos marcos históricos encadeados pelo diagnóstico da situação da e sua horizontalidade na perspectiva do acesso, participação e aprendizagem a partir dos sistemas de ensino brasileiro. Assim:

\footnotetext{
Os sistemas de ensino devem organizar as condições de acesso aos espaços, aos recursos pedagógicos e à comunicação que favoreçam a promoção da aprendizagem e a valorização das diferenças, de forma a atender as necessidades educacionais de todos os estudantes" (BRASIL, 2008, p. 13).
}

A formação e consequente atuação dos professores possuem relação direta para com essas condições, dentre outros pressupostos, como o da transversalidade da educação, do atendimento especializado, a continuidade da escolarização, a participação da família e comunidade, acessibilidade urbanística e articulação intersetorial na implementação das políticas 
públicas. Neste sentido, destacam-se as ações do Atendimento Educacional Especializado. Sua função é legalmente destacada como "complementar e suplementar".

0 atendimento educacional especializado tem como função identificar, elaborar e organizar recursos pedagógicos e de acessibilidade que eliminem as barreiras para a plena participação dos estudantes, considerando suas necessidades específicas. As atividades desenvolvidas no atendimento educacional especializado diferenciam-se daquelas realizadas na sala de aula comum, não sendo substitutivas à escolarização. Esse atendimento complementa e/ou suplementa a formação dos estudantes com vistas à autonomia e independência na escola e fora dela (BRASIL, 2008, p. 11).

Uma vez que o AEE se concentra em atendimentos específicos para necessidades específicas, sendo este complementar e/ou suplementar ao ensino na sala de aula comum, é fundamental que os professores que se encontram à frente desta educação e deste ensino nas salas de aula possuam o mínimo de formação que contemple a Educação Inclusiva, para que de fato o AEE se instale de maneira complementar ao ensino ofertado e não seja o único a promover a prática na perspectiva da inclusão.

Destarte, nota-se a importância da disseminação e efetividade dos estudos relacionados ao campo inclusivo na formação dos professores: todos eles, e não apenas aqueles que seguirão os caminhos do AEE. As legislações, bem como o próprio conceito de Inclusão, fazem entender que o preparo docente contribui para a Educação Inclusiva e o atendimento ao aluno com necessidades educacionais específicas no sentido atitudinal, metodológico, instrumental, programático e comunicacional, alcançando desta forma a acessibilidade em seu sentido amplo dentro dos muros escolares.

\section{Educação Inclusiva no currículo dos cursos da UNEB e UEMG}

Refletindo sobre a Educação Inclusiva na formação inicial docente, os cursos de Licenciatura em Artes visuais da Universidade Estadual da Bahia e Universidade Estadual de Minas Gerais, é visto um comparativo entre os dois currículos. De modo geral junto à realidade baiana e em consonância com a legislação federal, no que tange a Educação Inclusiva, na Bahia se elaborou o documento "Diretrizes da Educação Inclusiva no Estado da Bahia" (BAHIA, 2017), onde são replicados os elementos da norma nacional e são suscitados alguns aspectos da realidade do Estado.

No contexto de implementação da LBI, este documento contribui como um parâmetro institucional para a implementação de políticas públicas para o acesso à educação inclusiva. No 
contexto sociocultural baiano, as memórias sobre o percurso quanto as práticas de inclusão educacional são explicitadas pela experiência e iniciativas do estado e da sociedade civil:

Na Bahia, em meados do século XX, o contexto político-educacional não se diferenciava do quadro nacional apresentado: a então Educação Especial era assumida por iniciativas não-governamentais, como o Instituto de Cegos (1933) e 0 Instituto de Reabilitação de Deficientes Motores (1956). Com a fundação do Instituto Pestalozzi (1954), durante a gestão do Secretário de Educação da Bahia, o Sr. Dorival Passos (1950-1955), [...] conforme determinava a Constituição Brasileira de 1947, visto que, na época, não havia nenhuma lei estadual que regulamentasse a sua autonomia administrativa e financeira (BAHIA, 1976, p. 13).

Deste modo o Estado da Bahia, em relação ao que diz a legislação, obtém um documento que reforça a importância da Educação Inclusiva e que a valoriza junto à sociedade. Em relação a isso, se faz a partir de então o levantamento de dados relacionados à Universidade do Estado da Bahia (UNEB) no que se refere à educação formadora para o convívio, a promoção e o fomento dos processos inclusivos através dos professores de Arte formados pela instituição.

Fundada em 1983 e presente em todas as regiões geográficas de seu Estado, sendo a maior instituição pública do mesmo, a UNEB está estruturada em multicampi e oferece diversos cursos de graduação e pós-graduação. Um dos muitos cursos de Licenciatura ofertados pela Universidade é o de Artes Visuais, que, conforme informações públicas da instituição, é ofertado em dez polos/unidades de ensino.

Considerando a demanda de formação de professores nas comunidades onde a UNEB se insere (UNEB, 2012), a oferta de cursos de Licenciatura está vinculada ao Programa de Formação de Professores da Educação Básica (PARFOR), conhecido também como Plataforma Freire, resultado de uma parceria entre a UNEB e o Ministério da Educação (MEC).

A universidade diz que embora se constitua como uma proposta por parte do Governo Federal, o PARFOR representa mais um desafio para UNEB e se encaixa plenamente nos objetivos de formação, articulação e atendimento às demandas das comunidades (UNEB, 2013).

Para entender a discussão acerca do currículo do curso de Licenciatura em Artes Visuais da universidade, é importante saber que O PARFOR é destinado aos professores em exercício das escolas públicas estaduais e municipais sem formação adequada à LDB (UNEB, 2013).

Sendo assim, por meio desta iniciativa, a partir da criação do programa, os docentes que ministram suas aulas sem a formação adequada podem se graduar em diversos cursos de licenciatura, que tem como foco "professores em exercício das escolas públicas. 
Assim, a estruturação de componentes curriculares segue um formato correspondente a este público-alvo. Porém, a descrição deste currículo e exposição dos componentes e eixos que o integram não se fazem disponíveis para acesso com transparência e/ou facilidade.

Ao pensar na educação inclusiva na formação de professores de Artes Visuais na Universidade do Estado de minas Gerais (UEMG), nota-se que a universidade oferece 115 cursos de graduação na modalidade presencial. Diversos deles compõem o campo da educação, sendo um destes cursos o de Licenciatura em Artes Visuais instituído no campus da Escola de Design, na cidade de Belo Horizonte. Segundo a Universidade, o curso "forma docentes (professores) que irão atuar no ensino de artes visuais nas escolas do nível fundamental e do nível médio" (UEMG, 2019, s. p).

A instituição, de forma a cumprir com a Lei de Acesso à Informação № 12.527 de 2011 (BRASIL, 2011), que regulamenta 0 direito constitucional de acesso dos cidadãos às informações públicas, mantém disponíveis no site da instituição todos os documentos analisados para a construção deste estudo que investiga os componentes curriculares do curso de Artes Visuais com foco na Educação Inclusiva.

Em qualquer instituição de ensino, seja da esfera pública ou privada, da educação básica ou superior, o Projeto Político Pedagógico (PPP) é de extrema importância, pois define a identidade, atuação e reúne justamente as propostas políticas (no sentido de formação de cidadãos), metodológicas e pedagógicas que busquem alcançar os objetivos educacionais estabelecidos. No caso da educação superior, feito o PPP da instituição, são realizados também os Projetos Pedagógicos de cada Curso (PPC).

Por meio da apresentação estabelecida em seu site oficial, a UEMG define o curso de Artes Visuais da instituição como formador de profissionais para as relações entre a Arte, a Educação e a Cultura, sendo o mesmo:

\footnotetext{
Alicerçado em uma tríade conceitual e prática que se traduz em três verbos - inovar, formar e investigar - o curso se volta para o desenvolvimento de atitudes, valores, sensibilidades e conhecimentos que propiciarão as bases para a formação do docente em artes visuais. A estrutura do curso se divide em três módulos compostos por conhecimentos contextuais, estruturais e integradores (UEMG, 2019, s. p, grifo nosso).
}

Já Projeto Pedagógico do Curso (aprovado em 2016) destaca como objetivo geral "formar profissionais com competências ou aptos para docência em Artes Visuais, com 0 propósito de desenvolver indivíduos autônomos, solidários, capazes de saber ser, saber conhecer, saber atuar, inovar como professores de arte [...] (UEMG, 2016, p. 12). 
Compreende-se dessa forma que, tanto no Estado da Bahia quanto em Minas Gerais, as Universidade Estaduais possuem suas próprias políticas pedagógicas, no entanto, a pesquisa parte de uma das raízes que conferem (ou não) à educação em Arte a valorização das diferenças e a educação inclusiva, que é a própria formação docente, pretendendo assim, buscar em ações políticas, inclusivas, pedagógicas e educacionais, informações que contemplem a efetiva inclusão nos currículos universitários.

\section{METODOLOGIA}

O percurso metodológico perpassa os caminhos da investigação de carácter bibliográfico e documental, isto é, inserir o pesquisar em uma realidade com que já foi produzido cientificamente a partir do registro do tema pesquisado (MACEDO, 1995). Nesse sentido, como instrumentos de pesquisa, utilizou-se por meio da análise dos Projetos Políticos Pedagógicos dos cursos de Artes Visuais da Universidade do Estado da Bahia e Universidade do Estado de Minas Gerais, e do levantamento de dados legais amparados pela LBI (Lei $\left.n^{0} 13.146 / 15\right)$.

Além disso, preocupou-se em analisar e comparar os currículos dos cursos de licenciatura das instituições, visto que as realidades das Universidades com base nesses documentos foram debatidas e comparadas entre si, bem como frente ao que diz a legislação, caracterizando a pesquisa como documental e comparativa.

Não obstante, a pesquisa possui natureza qualitativa, segundo Severino (2007), as principais fontes de pesquisa contribuem para qualificar a pesquisa, proporcionando condições de manifestar o objeto, contribuindo para delinear a investigação e destacar a temática.

Portanto, com essa finalidade é possível descrever as principais diferenças e contribuições dos cursos para a educação inclusiva visando a reflexão crítica da tríade entre a formação dos professores, os direitos dos estudantes com deficiência e a aparente realidade apresentada nos documentos, Projetos Pedagógicos e currículos analisados.

\section{RESULTADOS E DISCUSSÃO}

Os resultados destacados, ocorrem a partir da comparação dos currículos e PPCs dos cursos de Artes Visuais da UNEB e UEMG, além disso, preocupou-se em dialogar com esses documentos, a fim de encontrar aparatos pedagógicos que possam corroborar com cursos de 
licenciatura a partir de efetiva inclusão, ou seja, componentes que sejam capazes de dar suporte aos futuros professores.

Ao analisar o PPC e os componentes curriculares da UNEB, é visto que apesar de ser limitada a identificação das informações sobre o curso de Licenciatura em Artes Visuais e seu currículo na plataforma oficial da Universidade, a autora Trigo aponta em sua pesquisa a história da criação do currículo de Artes Visuais e de seus eixos estruturantes, e apresenta as características sob as quais se teve a formação curricular do curso na instituição (TRIGO, 2014). Em sua pesquisa sobre essa estrutura e componentes, não se faz presente em seus levantamentos junto ao currículo e aos seus eixos nenhuma menção à Educação Especial e/ou Inclusiva.

Divulgado em uma plataforma online não pertencente à Universidade e/ou seu site oficial, de maneira com que o acesso e a localização das informações e do próprio documento se faz de forma dificultada, o "Currículo Reformulado" do curso de Licenciatura em Artes Visuais da UNEB aponta as informações necessárias para esta análise (BRASIL, 2013).

Dentre as características apresentadas pela estrutura curricular, umas das prioridades são as "abordagens artísticas e pedagógicas centradas no desenvolvimento da autonomia sensível e intelectual do professor-aluno", e seu objetivo geral se concentra em "qualificar educadores já atuantes em artes visuais na escola, através de conhecimento prático e teórico das artes visuais, desenvolvendo sua sensibilidade, percepção, criatividade e reflexão, sempre respeitando a característica metodológica, avaliativa e expressiva da área" (UNEB, 2013, p. 56).

Dentre os três objetivos específicos presentes no documento, não há nenhuma referência ao preparo e fomento da docência na, e para a Educação Inclusiva. Em meio às Competências Gerais, Específicas e Habilidades, se fazem presentes como competências do Projeto Pedagógico a "Responsabilidade social e compromisso cidadão", a "Capacidade para atuar em novas situações" e a "Valorização e respeito pela diversidade e multiculturalidade".

Desta forma, compreende o apreço à diversidade, porém o mesmo se dá de maneira geral, não sendo apontadas medidas e competências especificas para a sua promoção, sendo que o mesmo documento as classifica como competências gerais. São, ainda, apresentadas uma série de competências básicas, habilidades e competências específicas, mas nelas não são mencionados temas e ações referentes à Educação Especial e Inclusiva.

Os componentes da matriz curricular do curso estão divididos em quatro eixos. Nos detalhamentos dos componentes de cada um destes, fazem presentes as disciplinas Educação Especial e Libras no primeiro eixo (Articulador de Conhecimentos Básicos-Científicos, Culturais e 
Profissionais). Nos demais eixos, não são apresentados componentes referentes à inclusão no processo de formação dos professores.

Dentre as disciplinas ofertadas no curso que mantém diálogo junto à educação inclusiva, se fazem presentes as de Educação e Diversidade, que envolve e trabalha a "Evolução e novos paradigmas da Educação Especial". Ética, cidadania, sociedade inclusiva e educação especial", e a disciplina de Libras, que aborda a história, educação, cultura e identidade da comunidade surda e de sua língua oficial.

No contexto inclusivo, a mediação docente com o componente de Artes está estruturada de modo a contribuir com a execução de ações para o desenvolvimento dos discentes e 0 acesso à educação e às estratégias para a inclusão. No que tange o acesso ao currículo que estrutura o curso de Licenciatura em Artes Visuais ofertado pela universidade, as informações são escassas no site oficial da instituição e apenas fragmentos são localizados ao longo de outros documentos.

De modo geral, a pesquisa online e pública sobre o curso ofertado pela universidade é prejudicada com a escassez de informações e com a estrutura dificultadora da plataforma, que ora identifica o curso de artes visuais em seus destaques, ora o desconhece.

Desse modo, não são encontrados nas informações sobre o curso de Licenciatura em Artes Visuais ofertado pela UNEB documentos correspondentes à estruturação curricular em sua plataforma oficial de divulgação, sendo o currículo do curso divulgado por outras plataformas de comunicação. Os eixos temáticos ou quaisquer ações que tangenciam a diversidade e, em especial, a Educação Inclusiva, presentes no Projeto Pedagógico, são de difícil acesso uma vez que se fazem indisponíveis por meio do site oficial da instituição, e requer muito tempo e disposição para que o documento seja encontrado e acessado.

No que se refere a UEMG, pode-se destacar que há um contexto histórico que prefacia a instituição. A universidade, possui sua sede na capital mineira, está presente em várias cidades e regiões do estado, se configurando assim como multicampi. Dentre os seis objetivos específicos descritos no PPC, muito se fala em diversas compreensões que se fazem importantes para o Professor de Arte, mas em nenhum momento se especificam ações necessárias, por meio dos objetivos, de formação para a diversidade.

De acordo com o currículo do curso, os eixos das disciplinas ofertadas devem estar junto à concepção do Artista-Professor-Pesquisador, sendo este "um profissional capaz de aliar os processos de produção artística: domínio da técnica e modos de fazer; com pesquisa histórica, estética e de materiais; e com o exercício da docência: saber fruir e ensinar arte" (UEMG, 2016, p. 19). 
Assim, todos os eixos da disciplina compactuam com essa concepção e fomentam essa estrutura, sendo eles: Eixo Bidimensionalidade (disciplinas de Expressão e Representação Gráfica); Eixo Tridimensionalidade (Representação e Expressão Tridimensional); Tecnologias Contemporâneas; Eixo Complementar e Eixo Psicopedagógico.

Dentre todos os eixos presentes no Projeto Pedagógico, nota-se um foco à docência apenas no último eixo, enquanto os demais estão mais voltados à produção, representação e fruição. Dentre as dez disciplinas que compõem o Eixo Psicopedagógico, apenas uma está ligada à Educação Inclusiva, sendo a disciplina de Libras, que tem sua carga horária inferior à maioria das disciplinas (podendo ser de $30 \mathrm{~h} / \mathrm{a}$ ou $36 \mathrm{~h} / \mathrm{a}$ ). Vale lembrar que a Lei n. ${ }^{0} 10.436$, de 24 de abril de 2002, torna o ensino de LIBRAS obrigatório nos cursos de Licenciatura e Pedagogia (BRASIL, 2002).

Dentre a exposição de nomenclaturas e a descrição das disciplinas ofertadas, a que mais se aproxima, além da LIBRAS, de um diálogo pela e para a diversidade é a disciplina "Fatores Filosóficos" que, segundo as informações prestadas, aborda direitos humanos, diversidade religiosa, sexual, de faixa geracional e direitos educacionais de adolescentes e jovens em cumprimento de medidas socioeducativas. Ainda assim, não se faz presente nenhuma menção à Educação Especial e Educação Inclusiva.

De acordo com as informações presentes no PPC institucional, fica evidente que a formação de professores de Arte pela Universidade contempla a Educação Inclusiva apenas no que se refere a legislação, e não fomenta, em suas disciplinas, uma discussão que prepare, de fato, os sujeitos para atuarem junto às Pessoas com Deficiência.

No capítulo intitulado "Perfil do Professor que se Pretende Formar", aparece a primeira menção à Educação Especial Inclusiva. Nesta menção, a fim de explicitar o que a formação do profissional do curso de Licenciatura em Artes Visuais deve garantir, são destacados dois tópicos que garantem o equilíbrio de conteúdo, sendo um deles para professores que irão atuar na educação não formal e ambientes diferenciados aos da sala de aula e o outro com uma direção, descreve que atuação docente e multidisciplinar, voltada para educação infantil, ensino fundamental e médio, além das modalidades como Educação de Jovens e Adultos (EJA), Educação Inclusiva, Educação Profissional e Tecnológica, Educação do Campo, Educação Escolar Indígena, Educação a Distância, Educação Quilombola e com integração, ampliando campos característicos e/ou interdisciplinares (UEMG, 2016).

Ainda, é mencionado que "o perfil do professor de Arte deve estar sob a óptica da interação social e afetiva, integradora, construtiva e relacional" (UEMG, 2016, p. 27). Os trechos aqui trazidos, apesar de poucos, sucintos e sem riqueza de detalhes, mostra uma preocupação 
formadora para com a interdisciplinaridade e às várias modalidades da educação, mas não norteia estratégias específicas para essa formação e não apresenta uma disciplina que contemple todas essas modalidades e perspectivas que se fazem presentes na educação formal.

No ano de 2017, houve a estruturação de um novo currículo, deixando-o mais voltado ao Professor-Artista. No que diz respeito à docência, à interdisciplinaridade e às modalidades de educação nas quais esses profissionais enquanto Professores de Arte encontram, não houve mudanças significativas.

A abordagem comparativa incorporada nesta investigação permite a discussão de que ambas as Universidades, apesar da riqueza artística de seus Projetos Pedagógicos dos cursos de Artes Visuais, possuem fragilidades no que diz respeito à diversidade no aspecto inclusivo de forma clara e disseminada. Todos os documentos analisados tratam da Inclusão no sentido macroscópico, isto é, sem especificações curriculares que sustentem a preparação dos professores para a Educação Inclusiva de fato.

Apesar dos amparos de políticas públicas voltadas para a Educação Inclusiva, e dos reconhecidos avanços que a mesma alcançou nos últimos anos, com base nos documentos analisados, não se tem uma preocupação e uma promoção efetiva do ensino pautado na Inclusão nos cursos de Artes Visuais de ambas as Universidades.

A análise dos componentes curriculares presentes na grade dos cursos aponta uma preocupação não somente na formação dos professores de Arte, mas também na legislação, uma vez que aponta os direitos dos estudantes com deficiência, mas oferecem poucas medidas para que eles sejam fomentados e assegurados de forma ampla, e não minimamente como se vê neste e em outros cursos de licenciatura.

\section{CONSIDERAÇÕES FINAIS}

No que tange a Educação Inclusiva e Educação Especial na formação de professores por meio dos cursos de licenciatura aqui pautados, a presença de disciplinas e eixos temáticos que contemplem a discussão se fazem mínimas, a princípio como forma de cumprimento da legislação - o que se faz presente por meio do ensino de LIBRAS. Ainda, há uma lacuna no que diz respeito às informações dos cursos e dos currículos estruturantes, em especial por parte da UNEB, que não faz disponível o Projeto Pedagógico por meio de sua plataforma oficial, sendo 0 mesmo encontrado na internet.

Os documentos disponíveis apontam a diversidade de forma genérica e muito superficial, não proporcionando eixos temáticos para o grupo que requer da Educação Inclusiva, 
bem como ocorre com outros grupos. Tudo aquilo que norteia a pluralidade e diversidade aparece como forma de valorização das diferenças, do subjetivo, mas não são levantadas medidas para este alcance, nem são postas práticas visando essa formação para 0 atendimento de diferentes grupos educacionais.

A investigação ainda permite observar que mesmo importo de forma complementar e/ou suplementar, o AEE se faz como a principal mediação inclusiva nas escolas uma vez que os professores da sala de aula comum, em sua formação, a qual, não são preparados o suficiente para atender os educandos em suas necessidades específicas em âmbito educacional

Assim, se torna ainda mais necessário o diálogo e o trabalho em conjunto dos Professores de Apoio, Professores do AEE e Professores de Arte, uma vez que a união dos conhecimentos adquiridos ao longo da formação desses profissionais pode proporcionar um atendimento mais adequado aos direitos e necessidades do estudante com deficiência, sendo que o professor de Arte teve esta formação negligenciada em seu currículo, conforme observado nos documentos das universidades.

Em relação ao acesso às informações e aos currículos, a UNEB possui uma dificuldade no que diz respeito à divulgação de seus documentos. Suas publicações, se comparadas às da instituição mineira, ainda se fazem de forma quase extinta, não tendo sua matriz curricular divulgada de forma facilitada. A respeito disso, a UEMG se faz à frente no que diz respeito ao acesso às informações públicas, uma vez que traz em sua plataforma oficial de comunicação todos os dados presentes nesta investigação.

É importante, ainda, ressaltar que no currículo da UEMG e nas informações da UNEB não foram encontradas quaisquer menções à Tecnologia Assistiva e/ou Comunicação Alternativa, e, a partir de então, cabe uma nova reflexão para se analisar se tais competências devem ficar somente ao cargo dos Professores do AEE ou se deveriam ser de domínio e conhecimento de todos os professores de arte, uma vez que tais habilidades incluem 0 estudante com deficiência e facilitam a sua aprendizagem.

Portanto, não podemos afirmar que as temáticas do contexto inclusivo não se fazem presentes por meio dos diálogos e das vivências do dia a dia nas Universidades referidas, mas sim, apontar essa fragilidade que corresponde em ambos os currículos, que não especifica e nem determina pautas específicas para se contemplar a temática, deixando a mesma para 0 acaso das aulas, dos momentos e das disciplinas.

Assim, sugerimos que a temática seja discutida no cotidiano e na formação de professores, mas tal ato não cai como uma afirmativa, e sim como uma esperança, ainda assim, é visto a 
necessidade de formação continuada, que proporcione autonomia e especificidade ao docente sobre educação inclusive, preenchendo de forma acadêmica, lacunas deixas na formação inicial.

\section{REFERÊNCIAS}

BAHIA. Diretrizes Da Educação Inclusiva No Estado Da Bahia (Pessoas Com Deficiências, Transtornos Globais Do Desenvolvimento E Altas Habilidades/Superdotação). Disponível em: <http://escolas.educacao.ba.gov.br/educacaoespecial1>. Acesso em: 13 de jun. de 2021.

BARROS, José D.'Assunção. Igualdade e diferença: uma discussão conceitual mediada pelo contraponto das desigualdades. Revista Brasileira de Educação, v. 23, 2018.

BRASIL, Congresso Nacional. Constituição Nacional da República Federativa do Brasil. Brasília - Senado Federal: Centro Gráfico, 1988.

BRASIL, Lei 9.394, de 20 de dezembro de 1996. Estabelece as Diretrizes e Bases da Educação Nacional. (Lei de Diretrizes e Bases da Educação Nacional, LDB). Disponível em:

http://www.planalto.gov.br/ccivil_03/leis/L9394compilado.htm. Acesso em: 13 de jun. de 2020.

BRASIL, Lei n 10.436, de 24 de abril de 2002. Dispõe sobre a Língua Brasileira de Sinais Libras e dá outras providências. Disponível em:

http://www.planalto.gov.br/ccivil_03/LEIS/2002/L10436.htm. Acesso em: 13 de jun. de 2020.

BRASIL, Lei $n^{0} 12.527$ de 2011 - Lei de Acesso à Informação. Disponível em:

http://www.planalto.gov.br/ccivil_03/_ato2011-2014/2011/lei//12527.htm. Acesso em: 13 de jun. 2021.

BRASIL, Lei n 13.146, de 6 de julho de 2015. Institui a Lei Brasileira de Inclusão da Pessoa com Deficiência (Estatuto da Pessoa com Deficiência). Disponível em:

http://www.planalto.gov.br/ccivil_03/_ato2015-2018/2015/lei//13146.htm. Acesso em: 13 de jun. de 2021.

BRASIL, MEC/SECADI. Política Nacional de Educação Especial na Perspectiva da Educação Inclusiva. 2008. Disponível em:

http://portal.mec.gov.br/index.php?option=com_docman\&view=download\&alias=16690-politicanacional-de-educacao-especial-na-perspectiva-da-educacao-inclusiva-05122014\&ltemid=30192. Acesso em: 13 de jun. de 2021.

BRASIL, Programa Nacional de Formação de Professores da Educação Básica (PARFOR), 2013. Disponível em: https://www.gov.br/capes/pt-br/acesso-a-informacao/acoes-eprogramas/educacao-basica/parfor-1. Acesso em: 13 de jun. 2021.

BRASIL. Declaração de Salamanca e linha de ação sobre necessidades educativas especiais. Brasilia: Unesco, 1994.

CONTAGEM, Secretaria Municipal de Educação. Caderno de inclusão escolar do estudante com deficiência. Contagem, 2016.

DECLARAÇÃO DE SALAMANCA: Sobre Princípios, Políticas e Práticas na Área das Necessidades Educativas Especiais, 1994, Salamanca-Espanha. 
FRANCO, Vitor. Percursos Inclusivos No Ciclo De Vida Da Pessoa Com Deficiência. In: CANDEIAS, Adelinda Araújo. (Coordenação). Educação Inclusiva: Concepções e Práticas. CIEP. Évora. 2009

MACEDO, Neusa Dias de. Iniciação à pesquisa bibliográfica. Edições Loyola, 1995.

MANTOAN, Maria Teresa Eglér. A integração de pessoas com deficiência: contribuições para reflexão sobre o tema. Memnon, 2015.

REILY, L. O Ensino de Artes Visuais na Escola no Contexto da Inclusão. Caderno Cedes, Campinas, vol. 30, n. 80, p. 84-102, jan.-abr. 2010.

SEVERINO, Antônio. Joaquim. Metodologia do Trabalho científico. São Paulo: Cortez Editora. 2007.

TRIGO, Isa Maria Faria. DANDO NÓ EM PINGO D’ÁGUA: Plataforma Freire de Artes Visuais da UNEB: problemas, resultados e belezas. Olinda, 2014.

UEMG, Universidade Estadual de Minas Gerais. Projeto Pedagógico Curso - Artes Visuais Licenciatura, 2016. Disponível em:

https://www.uemg.br/images/PPC_Artes_Visuais_lic_E.Design_aprovado_coepe_16.12.16.pdf. Acesso em: 13 de jun. 2021.

UNEB, Universidade do Estado Da Bahia - UNEB. Currículo Reformulado, 2013. Disponível em: https://docplayer.com.br/5976629-Licenciatura-em-artes-visuais-curriculo-reformuladoplataforma-freire-uneb.html. Acesso em: 13 de jun. de 2021. 